\title{
Metode Pembelajaran Bahasa Arab Untuk Meningkatkan Kemampuan Membaca Kitab Kuning Mahasiswa Jurusan Pendidikan Bahasa Arab Fakultas Tarbiyah dan Ilmu Keguruan IAIN Palu
}

\author{
Ubadah \\ Institut Agama Islam Negeri Palu, Indonesia \\ Jl. Diponegoro No. 23, Kec: Palu Barat, Kota Palu, Sulawesi Tengah, 94221, Indonesia \\ Corresponding E-mail: ubadahyasin@gmail.com
}

\begin{abstract}
The research is about an effective method of learning Arabic language to improve speaking competence's students of Faculty of Tarbiyah IAIN Palu (study of Arabic Language Education Programe). The problem is how was the technique used by the lectures when taught Arabic language at Arabic language education programe, how was the students' competence of reading kitab kuning or Arabic script, and how was the technique use to improve students' competence of reading kitab kuning or Arabic script.

Its field research with descriptive qualitative which is use observation, interview, and documentation as intruments' research. The data is analysed by reduction, display, and verification.

The result shows the method used by the lectures was variative and different according to every lecture, and students' competence was below standard. On the other side, the technique use to improve students' reading competence by increase study of qawa'id, nahwu, and sharaf in class and outside.
\end{abstract}

Keywords: method, kitab kuning, Arabic language

\section{Abstrak}

Penelitian ini berkenaan dengan studi atas metode pembelajaran bahasa Arab yang efektif untuk meningkatkan kemampuan bercakap mahasiswa Fakultas Tarbiyah dan Ilmu Keguruan IAIN Palu (Studi pada Program Studi Pendidikan Bahasa Arab), yang permasalahannya meliputi bagaimana teknik yang dipergunakan oleh dosen bahasa Arab dalam mengajarkan bahasa Arab di Jurusan Pendidikan Arab (PBA), bagaimana kemampuan mahasiswa jurusan PBA dalam membaca kitab kuning atau naskah Arab yang tidak berbaris, dan bagaimana teknik pembelajaran dalam meningkatkan kemampuan membaca kitab yang tidak berbaris.

Penelitian ini adalah penelitian lapangan (field research) yang bercorak deskriptif kualitatif yang dipadu dengan data observasi, wawancara, dan dokumentasi. Analisis data dilakukan dengan cara reduksi data, display data, dan verifikasi data.Hasil penelitian menunjukkan bahwa metode yang dipakai oleh para dosen sangat variatif antara satu dosen dosen yang lain berbeda-beda, kemampuan membaca kitab mahasiswa juga masih di bawah standar. Adapun teknik pembelajaran untuk kitab yang tidak berbaris adalah dengan memperbanyak kajian tentang ilmu pendukung yaitu qawa'id, nahwu serta sharaf baik dalam perkuliahan maupun di luar perkuliahan.

Kata Kunci: Metode, Kitab Kuning, Bahasa Arab 


\section{Pendahuluan}

Setiap anak manusia pada dasarnya mempunyai kemampuan untuk menguasai setiap bahasa, walaupun dalam kadar dan dorongan yang berbeda. Adapun perbedaan-perbedaan tersebut adalah tujuan-tujuan pengajaran yang ingin dicapai, kemampuan dasar yang dimiliki, motivasi yang ada di dalam diri dan minat serta ketekunannya. ${ }^{1}$

\section{Belajar Bahasa Arab (asing)} berbeda dengan belajar bahasa ibu, oleh karena itu prinsip dasar pengajarannya harus berbeda, baik menyangkut metode (model pengajaran), materi maupun proses pelaksanaan pengajarannya. Bahasa Arab yang kini telah diakui oleh dunia sebagai bahasa internasional, tentu hal ini akan sangat memiliki andil yang signifikan dalam improvisasi dan kompetisi pada level dunia internasional. Hal ini bukan saja dalam aspek perkembangan kebahasaan dan ilmu kebahasaan, akan tetapi lebih dari itu, yaitu improvisasi dalam sector metodologi dan teknik pembelajarannya. ${ }^{2}$ Statement ini tentu dapat dibuktikan secara konkret dan faktual dalam proses pembelajaran bahasa Arab, dimana akhir-

1 Lihat Abdul Aziz bin Ibrahim al-Ushaili. Psikolinguistik Pembelajaran Bahasa Arab, Terjemahan Oleh Jailani Husni, (Bandung: Humanora, 2009) Cet I, h. 101 -105 akhir ini banyak bermunculan model-model dan teknik pembelajaran bahasa Arab yang interaktif dan inovatif yang tentunya akan menambah gairah peserta didik dalam mempelajari bahasa Arab secara simultan dan berkelanjutan. Hal ini tentu harus disambut oleh para tenaga pendidik bahasa Arab untuk direalisasikan secara aktif dan kreatif, sehingga proses pembelajaran bahasa Arab berlangsung maksimal dan terintegrasi dalam tujuan pembelajaran yang ingin dicapai.

Dari latar belakang di atas, penulis melakukan penelitian yang berkaitan dengan teknik pembelajaran bahasa Arab yang selama ini diterapkan oleh para dosen di Lingkungan Institut Agama Islam Negeri (IAIN) Palu khususnya pada Fakultas Tarbiyah dan Ilmu Keguruan Prodi Pendidikan Bahasa Arab. Adapun yang menjadi pokok permasalahan dalam penelitian ini adalah "bagaimana teknik pembelajaran bahasa Arab yang diterapkan oleh para dosen PBA dalam meningkatkan kemampuan membaca naskah Arab (kitab kuning) Mahasiswa di IAIN Palu Prodi PBA"

2 Zulhannan, Teknik Pembelajaran Bahasa Arab Interaktif, (Jakarta ; Raja Grafindo Persada 2014) Cetakan I, hlm. 3 
Dari pokok permasalahan tersebut, dirumuskan sub permasalahan sebagai berikut: 1) Bagaimana teknik pembelajaran bahasa Arab yang selama ini diterapkan dalam pembelajaran bahasa Arab di Prodi PBA IAIN Palu?, 2) Bagaimana kemampuan Mahasiswa Prodi PBA IAIN Palu dalam membaca dan memahami teks yang berbahasa Arab dan apa saja kendala yang dihadapi?, dan 3) Bagaimana teknik pembelajaran untuk meningkatkan kemampuan membaca teks bahasa Arab yang tidak berbaris Mahasiswa Prodi PBA FTIK IAIN Palu?

Berdasarkan rumusan masalah di atas, maka tujuan penelitian ini, yaitu: Untuk mengetahui teknik pembelajaran apa saja yang selama ini diterapkan oleh para Dosen dalam pembelajaran bahasa Arab di Prodi PBA FTIK IAIN Palu, untuk mengetahui kemampuan dan kendala yang dihadapi mahasiswa Prodi PBA FTIK IAIN Palu dalam membaca naskah Arab (kitab tanpa baris), dan untuk mengetahui teknik pembelajaran yang efektif dalam meningkatkan kemampuan mahasiswa Prodi PBA FTIK IAIN Palu dalam membaca teks Arab yang tidak berbaris.
Penelitian ini akan menyoroti model pembelajaran yang selama ini diterapkan dalam pengajaran bahasa di IAIN Palu khususnya pada Prodi Pendidikan Bahasa Arab Fakultas Tarbiyah dan Ilmu keguruan terutama dalam hal penggunaan teknik pembelajaran bahasa Arab dalam meningkatkan kemampuan membaca naskah/teks Arab mahasiswa IAIN Palu. Mengingat luasnya cakupan tentang pembelajaran bahasa Arab ini, maka yang menjadi kajian utama dalam penelitian ini adalah bagaimana mengimplementasikan teknik pembelajaran bahasa Arab yang efektif dalam meningkatkan kemampuan mahasiswa membaca naskah atau teks bahasa Arab tanpa tanda baca/baris.

\section{Metode Penelitian}

Jenis penelitian ini adalah penelitian kualitatif. Penelitian kualitatif ini sering disebut penelitian naturalistik karena penelitiannya dilakukan pada kondisi yang alamiah (natural setting) dimana peneliti adalah sebagai instrumen kunci. ${ }^{3}$ Penelitian ini berfokus pada pendeskripsian teknik pembelajaran Bahasa Arab yang efektif yang bisa meningkatkan kemampuan

\footnotetext{
${ }^{3}$ Sugiyono, Memahami Penelitian Kualitatif (Cet. I; Bandung: Alfabeta, 2008), h. 1
} 
mahasiswa dalam membaca naskah atau teks Arab tanpa tanda baca pada Fakultas Tarbiyah dan Ilmu Keguruan Jurusan Pendidikan Bahasa Arab IAIN Palu. Dalam Penelitian ini, peneliti sendiri yang menjadi instrumen kunci dalam mendeskripsikan dan menganalisis penerapan model pembelajaran bahasa Arab oleh dosen Bahasa Arab pada Jurusan PBA. Adapun Rancangan penelitian yang digunakan adalah rancangan studi kasus.

\section{Beberapa Metode dalam Pembelajaran}

\section{Bahasa Arab}

Secara sederhana, metode pengajaran bahasa Arab dapat digolongkan menjadi dua macam, yaitu: pertama, metode tradisional/klasikal dan kedua, metode modern. Metode pengajaran bahasa Arab tradisional adalah metode pengajaran bahasa Arab yang terfokus pada "bahasa sebagai budaya ilmu" sehingga belajar bahasa Arab berarti belajar secara mendalam tentang seluk-beluk ilmu bahasa Arab, baik aspek gramatika/sintaksis (qawaid al-nahwu), morfem/morfologi (qawaid al-sharf) ataupun sastra (adab). Metode yang berkembang dan masyhur

\footnotetext{
${ }^{4}$ Muammad Abdul Qadir Ahmad, Thurqu Ta'lim al-Lughah al-'Arabiyah, Cet. I, (Beirut Libanon: Al-Maktabah al-Amawiyyah, 1983) h. 5-8
}

digunakan untuk tujuan tersebut adalah Metode qawaid dan tarjamah. Metode tersebut mampu bertahan beberapa abad, bahkan sampai sekarang pesantrenpesantren di Indonesia, khususnya pesantren salafiah masih menerapkan metode tersebut. Hal ini didasarkan pada hal-hal sebagai berikut: Pertama, tujuan pengajaran bahasa Arab tampaknya pada aspek budaya/ilmu, terutama nahwu dan ilmu sharaf. Kedua kemampuan ilmu nahwu dianggap sebagai syarat mutlak sebagai alat untuk memahami teks/kata bahasa Arab klasik yang tidak memakai harakat, dan tanda baca lainnya. Ketiga, bidang tersebut merupakan tradisi turun temurun, sehingga kemampuan di bidang itu memberikan "rasa percaya diri (gengsi) tersendiri di kalangan mereka".

Metode pengajaran bahasa Arab modern adalah metode pengajaran yang berorientasi pada tujuan bahasa sebagai alat. ${ }^{4}$ Artinya, bahasa Arab dipandang sebagai alat komunikasi dalam kehidupan modern, sehingga inti belajar bahasa Arab adalah kemampuan untuk menggunakan bahasa tersebut secara aktif dan mampu

lihat juga Hasan Ja'far al-Khalifah, Fushul fi Tadris al-Lughah al- "Arabiyah, (Riyadh: Maktabah Rusydi, 2004) h. 17 
memahami ucapan/ungkapan dalam bahasa Arab. Metode yang lazim digunakan dalam pengajarannya adalah metode langsung (tariqah al - mubasyirah). Munculnya metode ini didasari pada asumsi bahwa bahasa adalah sesuatu yang hidup, oleh karena itu harus dikomunikasikan dan dilatih terus sebagaimana anak kecil belajar bahasa. $^{5}$

Ada beberapa metode yang dianggap paling populer dan masih dipergunakan dalam pembelajaran bahasa Arab, diantaranya:

\section{a. Metode Gramatika Tarjamah} (الطريقة القواعد والترجمة)

Metode ini merupakan gabungan antara metode gramatika dengan metode terjemah. ${ }^{6}$ Metode ini biasa juga diistilahkan dengan metode tradisional. Hal ini disebabkan metode ini memfokuskan kajian pada teks bahasa dan informasi sekitar kebahasaan. Namun tidak berarti bahwa metode inilah yang tertua. Term tradisional yang melekat pada metode ini,

\footnotetext{
${ }^{5}$ Rusydi Ahmad Thuaimah, Op. Cit. h. 610

6 Disadur dari Mulijanto Sumardi, Pengajaran Bahasa Asing, Sebuah tinjauan dari Segi Metodologi. (Jakarta: Bulan Bintang. 1975) h. 37 Lihat juga Tayar Yusuf. Metodologi pengajaran
}

menurut Subyakto $^{7}$ lebih merupakan pencerminan yang paling tepat dari cara bahasa-bahasa Yunani kuno dan Latin diajarkan selama berabad-abad.

Landasan teoritis dari metode gramatika terjemah ini adalah bahwa ada satu universal logic atau logika semesta yang merupakan dasar semua bahasa di dunia ini, dan bahwa tata bahasa adalah bagian dari logika dan filsafat. ${ }^{8}$ Dengan demikian, belajar bahasa dapat memperkuat kemampuan berpikir logis, memecahkan masalah, dan kemampuan menghafal.

Metode ini tidak memberikan perhatian bercakap secara intensif dan peserta didik cenderung pasif dan materi pelajarannya terdiri atas buku nahwu (gramatika), kamus atau mufradat, dan teks bacaan. Dan yang paling menonjol adalah bahasa pengantarnya adalah bahasa ibu pelajar. $^{9}$

\section{b. Metode Langsung (الطريقة المباشرة)}

Dalam bahasa Arab, metode ini dinamakan thariqah al-mubasyirah, yang muncul di Eropa sekitar abad ke 19 sebagai

Agama dan Bahasa Arab. Cet. I, (Jakarta: PT.Raja Grafindo Persada. 1995) h. 171

7 Sri Utari Subyakto, Op. Cit. h. 11

8 Ibid. h. 12

${ }^{9}$ Lihat Mukhtar al-Thahir Husain, Op. Cit. h. 221 
reaksi dan ketidakpuasan terhadap metode gramatika tarjamah. ${ }^{10}$ Asumsi metode ini bertentangan secara diametral dengan metode gramatika tarjamah. Asaumsi dari metode langsung adalah bahwa proses pembelajaran bahasa Arab sama dengan pembelajaran bahasa ibu, yang berarti bahwa penggunaan bahasa tujuan/asing harus dilakukan secara langsung dan intensif dalam berkomunikasi melalui mendengar dan berbicara. Sedangkan keterampilan membaca dan menulis dapat dikembangkan kemudian. Penggunaan bahasa ibu dihindari sama sekali (ibti'ad an lughah al-ummi) dan peserta didik dibiasakan berpikir dan praktiik dalam bahasa asing/tujuan. ${ }^{11}$

Dengan demikian, dalam metode langsung, pengajar atau pendidik bahasa Arab langsung menggunakan bahasa tujuan/asing ketika menjelaskan materi ajar dalam suati proses pembelajaran dan bahasa persrta didik "haram" untuk dipergunakan. Menurut A. Fuad Effendi, salah satu pondok pesantren yang konsisten menerapkan metode ini adalah Pondok Modern Gontor Ponorogo. ${ }^{12}$

c. Metode Membaca (الطريقة القراءة)
Sama halnya dengan metode sebelumnya, kemunculan metode membaca ini juga merupakan reaksi dari metode langsung yang hanya memprioritaskan kemahiran berbicara dan kurang memberikan perhatian pada kemahiran membaca dan menulis. Atas dasar inilah, para pakar pendidik dan pakar bahasa termotivasi untuk mencetuskan sebuah gagasan metode kontemporer sesuai dengan perkembangan pembelajaran bahasa pada waktu itu. Meskipun dinamakan metode membaca, tidak berarti bahwa bahwa proses pembelajaran terbatas pada latihan membaca, latihan menulis dan berbicara juga diberikan kendatipun dengan porsi yang terbatas.

Tujuan utama metode ini adalah kemahiran membaca, yaitu agar peserta didik mampu memahami teks untuk keperluan studi mereka. ${ }^{13}$

\section{d. Metode Audiolingual الطريقة)}

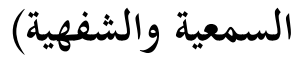

Metode ini muncul dalam suasana Perang Dunia ke 2 di Amerika Serikat. Pada waktu itu diperlukan personalia yang lancer berbahasa asing untuk ditempatkan di

\footnotetext{
${ }^{10}$ Ibid, h. 230

${ }^{11}$ Ibid. h. 231
} 
beberapa Negara. ${ }^{14}$ Untuk keperluan tersebut, Departemen Pertahanan Amerika Serikat membentuk suatu badan yang bernama Army Specialized Training Program (ASTP) dengan bekerja sama 55 Universitas yang dimulai tahun 1943 dan betujuan agar peserta program dapat mencapai keterampilan berbicara dalam beberapa bahasa asing dengan pendekatan dan metode yang baru. Model ASTP tersebutlah yang kemudian menjadi cikal bakal dari Metode Audiolingual, setelah dikembangkan dan diberi landasan metodologis oelh berbagai universitas di Amerika terutama Universitas Michigan. Pada waktu yang bersamaan di Inggris juga dikembangkan Oral-approach yang sangat mirip dengan metode audiolingual. ${ }^{15}$

Asumsi metode ini adalah bahwa bahasa itu pertama-tama adalah ujaran dan kebiasaan. Oleh karena itu pengajaran harus dimulai dengan memperdengarkan bunyibunyi bahasa dan menjadikan bahasa sebagai kebiasaan dan harus diulang-ulang dengan teknik repetisi. Kegiatan bahasa harus diisi dengan dengan kegiatan berbahasa bukan mempelajari kiadahkaidah bahasa. Tujuan utama metode ini

\footnotetext{
${ }^{14}$ Mukhtar al-Thahir Hasan, Op. Cit. h. 239

${ }^{15}$ Op. Cit. h. 46
}

adalah penguasaan empat kemahiran berbahasa secara seimbang dengan urutan penyajian menyimak dan berbicara baru kemudian membaca dan menulis. ${ }^{16}$

\section{e. Metode Komunikatif الطريقة)} (الأتصالية)

Metode Audio lingual digunakan ecara luas sampai awal tahun enampuluhan. Setelah itu para ahli dan praktisi pengajaran mulai mengecamnya. Beberapa tahun kemudian muncullah metode komunikatif yang didasarkan atas asumsi bahwa setiap manusia memiliki kemampuan atau kompetensi bawaan yang disebut dengan "alat pemerolehan bahasa" (language acquisition Device/LAD). Oleh karena itu, kemampuan berbahasa bersifat kreatif dan lebih ditentukan oleh factor internal, sehingga relevansi dan efektifitas kegiatan pembiasaan dengan model latihan stimulusrespence-inforcment dipersoalkan. Asumsi berikutnya adalah bahwa penggunaan bahasa tidak hanya terdiri atas empat kemahiran berbahasa, akan tetapi mencakup beberapa kompetensi dalam kerangka komunikatif yang luas, sesuai 
dengan peran dari partisipan, situasi dan tujuan interaksi. ${ }^{17}$

\section{f. Metode Eklektik/Campuran} (الطريقة الإنتقائية)

Metode eklektik atau metode campuran ini merupakan gabungan dari unsure-unsur yang ada dari metode metode sebelumnya terutama yang terdapat dalam metode qawaid wa altarjamah dan metode al-mubasyirah. Metode ini memiliki asumsi bahwa tidak ada metode yang ideal, masing-masing memiliki kelemahan dan kekuatan; setiap metode mempunyai kekuatan yang dapat dimanfaatkan untuk mengefektifkan pembelajaran; tidak ada satu metode yang cocok untuk semua tujuan; yang paling vital dalam pembelajaran adalah memenuhi kebutuhan peserta didik; pendidik memiliki kewenangan untuk memilih metode yang sesuai dengan kebutuhan peserta didik. ${ }^{18}$

\section{Pengajaran bahasa Arab di} Perguruan Tinggi umumnya menggunakan metode eklektik, dan tentunya dengan berbagai alasan, antara lain, heteroginitas input mahasiswa, otoritas dosen yang

17 Ahmad Fuad Efendy, Op. Cit. h. 54-56

${ }^{18}$ Ibid h. 71 sangat tinggi, dan akses yang lebih cepat terhadap perkembangan terbaru dalam metodologi pembelajaran bahasa; ditambah lagi dengan kemajuan informasi dan teknologi dewasa ini terutama teknologi internet yang memudahkan orang mendapat akses informasi pemebelajaran yang mutakhir dan terkini.

\section{Teknik Pembelajaran bahasa} Arab

Sesungguhnya dalam setiap bahasa terdapat unsur-unsur yang dapat dilihat secara terpisah-pisah kendati antara yang satu dengan yang lain saling berhubungan erat sehingga terbentuk sebuah fenomena yang bernama bahasa. Dalam unsur bahasa tersebut terdapat unsur tata bunyi atau $a l$ ashwat (fonologi), kosa kata atau almufradat, tata kalimat atau al-nahwu, morfologi atau al-sharf, ataupun otografi (kitabah). Latihan unsur bahasa sangatlah vital bagi peserta didik. Karena ia merupakan partikulasi dari bahasa itu sendiri. ${ }^{19}$

Dalam pembelajaran bahasa Arab, terdapat beberapa teknik yang mendukung proses pembelajaran. Namun yang

19 Ahmad Fuad Efendy, Metodologi Pengajaran Bahasa Arab, ( Malang: Misykat, 2005) h. 81 
disajikan pada bagian ini adalah teknik pengajaran kemahiran berbahasa yang meliputi teknik pengjaran keterampilan menyimak, berbicara, membaca, dan menulis.

\section{Sistem Pembelajaran Bahasa}

\section{Arab yang Inovatif}

Hampir semua bahasa di dunia ini terdapat unsur-unsur yang dapat dilihat secara terpisah-pisah kendati satu sama lain saling berhubungan erat dan menyatu sehingga terbentuk sebuah fenomena yang bernama bahasa. Selain itu, performance dan kemampuan berbahasa juga bermacammacam, ada yang berbentuk lisan dan ada pula yang berbentuk tulisan. Ada yang bersifat reseptif (menyimak dan membaca), dan juga yang bersifat produktif (berbicara dan menulis). Dalam pembelajaran bahasa, terdapat beberapa sistim, terpadu, terpisahpisah, dan gabungan.

\section{Teknik Pembelajaran Bahasa} Arab di Jurusan Pendidikan Bahasa Arab Fakultas Tarbiyah dan Ilmu Keguruan

Proses pembelajaran bahasa Arab di Jurusan Pendidikan Bahasa Arab (PBA) FTIK IAIN Palu yang penulis amati selama ini, tenik yang digunakan oleh para dosen adalah variatif. Antara satu dosen dengan dosen yang lain berbeda dalam teknik pengajaran yang mereka pergunakan.

Dalam pengamatan penulis, ketika melaksanakan perkuliahan, terdapat dosen yang mengajarkan bahasa Arab yang lebih menitikberatkan pada teknik kemahiran istima' atau listening (menyimak) dengan cara lebih sering memperdengarkan percakapan melalui media elektronik seperti tape wireless (tape recoder). Dalam "kasus" seperti ini tentu mahasiswa hanya dituntut untuk bisa bercakap dalam bahasa Arab tanpa memerhatikan atau memoles kemampuan mereka untuk membaca naskah atau teks Arab. Karena secara umum, tujuan dari latihan menyimak ini adalah agar pebelajar dapat memahami ujaran dalam bahasa Arab, baik dalam konteks bahasa sehari-hari maupun dalam bahasa formil.

Selain teknik di atas, terdapat juga dosen yang mengajar bahasa Arab dengan teknik bacaan. Pada pembelajaran ini sang Dosen mengajar bahasa Arab dengan cara membaca wacana atau naskah sederhana yang berbahasa Arab yang berharakat disertai dengan analisa fungsi kata dalam sebuah kalimat. Model pengajaran seperti ini lebih menekankan pada teknik pembelajaran keterampilan membaca atau maharah alqira'ah. 
Selain teknik di atas, berdasarkan hasil obsevasi, terdapat juga dosen yang mengajarkan bahasa Arab di Jurusan Pendidikan bahasa Arab dengan teknik gabungan, yaitu menggabungkan dua teknik pengajaran kemahiran membaca dan menulis dimana mahasiswa menulis wacana yang ada di papan tulis atau slide kemudian dilakukan latihan membaca naskah atau wacana tersebut. Dalam konteks ini teknik yang dipergunkan adalah gabungan teknik kemahiran menulis dan membaca atau maharah alkalam wa al qira'ah. Namun, kemahiran menulis yang diterapkan pada pengajaran tersebut baru terbatas pada kemahiran merangkai huruf dan menguasai ejaandan bukan kemahiran untuk melahirkan dan menuliskan gagasan atau perasaan. Namun, seperti sudah dijelaskan bahwa dalam kemahiran menulis ada dua aspek yang diasah yaitu kemahiran membentuk huruf dan menguasai ejaan dan kemahiran menangkan pikiran dan perasaan.

Berdasarkan pemaparan hasil observasi di atas bisa dikatakan bahwa teknik pengajaran bahasa Arab di Jurusan Pendidikan Bahasa Arab FTIK IAIN Palu cukup variatif. Antara satu dosen dengan dosen yang lain berbeda dalam teknik pengajaran kendatipun dalam metode kadang-kadang terdapat kesamaan terutama penggunaan metode qawai'd wa a;tarjamah. Khusus teknik pengajaran dalam rangka meningkatakan kemampuan mahasiswa membaca naskah atau wacana bahasa Arab juga sudah dilakukan walau belum maksimal. Hal ini ditandai dengan adanya penerapan teknik pengajaran kemahiran membaca dimana dosen mengajarkan pada mahasiswa kosakata baru dari bacaan atau dari naskah bahasa Arab. Karena tujuan umum dari pengajaran membaca ini adalah agar para mahasiswa mampu membaca dan memahami teks yang berbahasa Arab.

Berdasarkan hasil wawancara diketahui pula bahwa terdapat juga dosen di Jurusan Pendidikan Bahasa Arab yang memakai teknik qira'ah dengan tujuan mahasiswa dapat membaca naskah Arab yang tidak berbaris.

Kemampuan membaca kitab yang tidak berbaris atau kitab kuning yang juga biasa dikenal dengan kitab gundul adalah modal dasar untuk bisa memahami makna atau isi dari suatu kitab. Sedangkan syarat 
dasar untuk bisa membaca dengan baik dan benar suatu naskah Arab yang tidak berbaris adalah dengan menguasai kaidah-kaidah bahasa Arab, baik itu nahwu (sintaksis) maupun sharaf (morfologi) dan ilmu turunannya.

Untuk bisa memahami kaidahkaidah bahasa Arab dengan baik dan benar yang notabene merupakan syarat primordial dalam kemampuan membaca dan memahami naskah Arab yang tidak berbaris, maka diperlukan usaha yang sungguhsungguh dari mahasiswa untuk belajar dan berlatih serta memperdalam penguasaan qawa'id atau kaidah-kaidah bahasa Arab.

Pembelajaran mata kuliah qawa'id di Jurusan Pendidikan Bahasa Arab dilaksanakan dalam dua semester, yaitu qawa'id 1 dan qawa'id 2. Namun untuk mahasiswa angkatan 2016, mata kuliah qawa'id ditiadakan dan dilebur dalam mata kuliah nahwu 1 dan 2 serta sharaf 1 dan 2. Hal ini dilakukan, karena mata kuliah qawa'id dan nahwu serta sharaf dianggap tumpang tindih dan biasa berulang materinya apalagi kalau dosennya berbeda. Karena itu, mata kuliah tersebut dilebur dalam mata kuliah nahwu 1 dan 2 serta sharaf 1 dan 2 dengan kurikulum yang berbasis KKNI.

Seperti telah dijelaskan di atas bahwa kemampuan membaca naskah Arab yang tidak berbaris berhubungan erat dengan penguasaan gramatika bahasa Arab atau qawa'id (nahwu dan sharf). Oleh karena itu, yang menjadi bagian dari penelitian ini adalah bagaimana teknik pengajaran materimateri pendukung tersebut dalam proses perkuliahan di Jurusan Pendidikan Bahasa Arab FTIK IAIN Palu. Materi-materi pendukung yang dimaksud tersebut adalah sebagai berikut:

1. Mata kuliah Bahasa Arab 1 dan 2

2. Mata kuliah Qawaid 1 dan 2

3. Mata kuliah Nahwu

4. Mata kuliah Sharaf

Berikut ini dijelaskan teknik pembelajaran keempat matakuliah di atas:

a) Teknik Pembelajaran Bahasa Arab 1 dan 2

Dalam proses pembelajaran bahasa Arab baik bahasa Arab 1 maupun bahasa Arab 2 atau lanjutan di Jurusan Pendidikan Bahasa Arab FTIK IAIN Palu, teknik kemahiran membaca teks sangat jarang dilakukan oleh para dosen pengajar bahasa 
Arab. Berdasarkan pengamatan penulis, dosen yang mengampuh mata kuliah ini ratarata mengajar bahasa Arab dengan teknik atau metode ceramah dan tidak ada latihan membaca teks. Kalaupun ada, maka bacaan itu hanya berkisar hiwar atau latihan percakapan dan itupun dengan teks hiwar yang berbaris.

Berdasrkan wawancara dan pengamatan penulis, mata kuliah bahasa Arab 1 dan 2 diajarkan dalam 2 semester yaitu smester satu dan semester dua, dan metode yang dipakai adalah metode ceramah dan tanpa ada teknik kemahiran membaca teks. Hal tersebut terjadi karena mayoritas mahasiswa belum sepenuhnya menguasai dasar-dasar bahasa Arab terutama mereka yang berlatar belakang sekolah umum.

b) Teknik Pembelajaran Qawa'id 1 dan 2

Mata kuliah qawa'id di Jurusan Pendidikan Bahasa Arab FTIK IAIN Palu dibagi dalam dua semester yaitu qawa'id 1 dan qawa'id 2. Untuk mata kuliah qawa'id 1 diajarkan pada semester 5 dan qawa'id 2 pada semester 6. Dalam proses pembelajaran mata kuliah qawa'id ini, teknik atau metode pembelajarannya adalah dengan membaca teks qawa'id dari buku rujukan kemudian dianalisa fungsi atau kedudukan kata perkata dalam struktur kalimat. Dalam pembelajaran tersebut juga mahasiswa disuruh membaca naskah qawaid tersebut. Namun, latihan kemahiran membaca ini tidak secara intensif dilakukan dan hanya membaca biasa saja. Memurut salah seorang dosen yang mengampuh mata kulaih qawa'id ini bahwa teknik pembelajaran yang dilakukan adalah dengan cara menjelaskan tentang bahasan atau materi qawa'id kepada mahasiswa secara komprehensip dan tidak ada latihan teknik membaca teks secara khusus karena waktunya yang tidak cukup, apalagi mata kuliah qawa'id ini hanya 2 sks dalam satu semester. Untuk mengasah kemampuan mahasiswa membaca teks Arab gundul, diperlukan kelas dan waktu yang khusus secara intensif. ${ }^{20}$

Berdasarkan penjelasan di atas dan pengamatan penulis, teknik pembelajaran qawa'id di Program Studi Pendidikan Bahasa Arab FTIK IAIN Palu adalah dengan teknik atau metode ceramah dan tanpa ada latihan teknik kemahiran membaca teks.

20 Ahmad Sehri bin Punawan, Dosen Tetap PBA, "wawancara" di Gedung Tarbiyah lantai 2 IAIN Palu Pada Tanggal 25 Juli 2017 
Materi qawaid diajarakan dengan cara menjelaskan materi bahasan dengan teknik ceramah. Hal ini disebabakan tidak adanya waktu yang cukup untuk latihan membaca naskah yang tanpa baris mengingat mata kuliah ini hanya 2 sks untuk satu semester. Karena itu diperlukan kelas khusus yang bisa membina dan melatih kemampuan mahasiswa dalam membaca kitab dan naskah Arab yang tidak berbaris.

c) Teknik Pembelajaran Nahwu

Mata kuilah Nahwu di Program Studi Pendidikan Bahasa Arab FTIK IAIN Palu diajarkan pada semester 3 setelah mata kuliah Bahasa Arab 2 pada semester dua. Bisa dikatakan bahwa matakuliah ini merupakan lanjutan atau pemantapan dari materi bahasa Arab 1 dan 2, sehingga materinya banyak yang sama namun bahasannya lebih luas dan komprehensif. Adapun teknik pembelajaran mata kuliah nahwu ini adalah teknik ceramah dengan menjelaskan secara komprehensif materi bahasan disertai latihan-latihan mengidentifikasi fungsi-fungsi kosa kata dalam struktur kalimat. Namun untuk latihan membaca teks "gundul" tidak ada sama sekali dengan alasan waktu yang tidak cukup. d) Teknik Pembelajaran Sharaf

Untuk mata kuliah sharaf, diajarkan pada semester 4 untuk angkatan di bawah 2016. Namun sejak angkatan 2017 mata kuliah sharaf ini dibagi didistribusikan dalam dua semester, yaitu semester 3 dan 4 yang terdiri atas sharaf 1 dan sharaf 2 yang masing-masing 2 sks. Mata kuliah ini adalah mata kuliah yang membahas secara tuntas morfologi bahasa Arab. Adapun teknik pemebelajarannya adalah dengan teknik ceramah dan diskusi atau tanya jawab seputar materi bahasan. Untuk latihan membaca kitab, berdasarkan pengamatan penulis, tidak ada latihan membaca teks.

Berdasarakan hasil pengamatan dan wawancara, bisa disimpulkan bahwa teknik pembelajaran mata kuliah pendukung kemampuan membaca kitab yang tidak berbaris atau kitab kuning tidak ada latihan kemahiran membaca kitab dengan alasan bahwa waktu yang ada tidak mencukupi ditambah lagi mata kuliah tersebut hanya 2 sks dalam satu semester. Oleh karena itu, diperlukan adanya waktu khusus atau kelas khusus yang melatih mahasiswa Jurusan Pendidikan Bahasa Arab untuk meningkatkan kemampuan mereka dalam membaca kitab yang tidak berbaris. 


\section{KESIMPULAN}

Berdasarkan hasil penelitian yang telah diuraikan tentang teknik pembelajaran bahasa Arab dalam rangka meningkatkan kemampuan membaca kitab mahasiswa Jurusan Pendidikan Bahasa Arab FTIK IAIN Palu, berikut penulis menyimpulkan beberapa hal yang berkaitan dengan permasalahan tersebut:

1. Teknik peembelajaran bahasa Arab di Jurusan Pendidikan Bahasa Arab FTIK IAIN Palu cukup variatif. Antara satu dosen dengan dosen yang lain berbeda dalam teknik pengajaran kendatipun dalam metode kadang-kadang terdapat kesamaan terutama penggunaan metode tradisional atau metode qawai'd wa al-tarjamah. Khusus teknik pengajaran dalam rangka meningkatakan kemampuan mahasiswa membaca naskah atau wacana bahasa Arab juga sudah dilakukan walau belum maksimal. Hal ini ditandai dengan adanya penerapan teknik pengajaran kemahiran membaca dimana dosen mengajarkan pada mahasiswa kosakata baru dari bacaan atau dari naskah bahasa Arab. Karena tujuan umum dari pengajaran membaca ini adalah agar para mahasiswa mampu membaca dan memahami teks yang berbahasa Arab.

2. Kemampuan mahasiswa jurusan Pendidikan Bahasa Arab dalam membaca teks bahasa Arab yang tanpa baris tidaklah maksimal bahkan ada yang sama sekali tidak mampu membaca naskah yang tanpa baris tersebut. Namun dalam beberapa kelas terdapat satu atau dua orang mahasiswa yang bisa membaca naskah yang tidak berbaris terutama mahasiswa yang berlatar belakang pendidikan Pondok Pesantren separti dari Ponpes Darul Istiqamah Ngata Baru, Ponpes Madinatul Ilmi Dolo maupun ponpes yang diluar Sulawesi.

Adapun kendala yang dihadapi adalah kurangnya penguasaan terhadap ilmu pendukung yaitu qawai'id atau gramatika bahasa Arab. Hal ini terjadi karena kurangnya waktu yang ada dalam proses pembelajaran. Kendala yang lain adalah tidak adanya bimbingin khusus yang mengajarkan teknik-teknik membaca kitab seperti pelatihan maupun halaqah yang khusus membina kemampuan membaca kitab. 


\section{DAFTAR PUSTAKA}

Ahmad, Muammad Abdul Qadir, Thuruqu

Ta'lim al-Lughah al-'Arabiyah,

Cet. I, Beirut Libanon: Al-

Maktabah al-Amawiyyah, 1983

Al-Khalifah, Hasan Ja'far, Fushul fi Tadris

al-Lughah al-'Arabiyah, Riyadh:

Maktabah Rusydi, 2004

Effendy, Ahmad Fuad, Metodologi Pengajaran Bahasa Arab. Malang: Penerbit Musykat, 2005.

Hermawan, Acep. Metodologi Pembelajaran Bahasa Arab, Bandung: Remaja Rosda Karya, 2011

Sumardi, Mulijanto, Pengajaran Bahasa Asing, Sebuah tinjauan dari Segi Metodologi. Jakarta: Bulan Bintang. 1975.

Subyakto, Sri Utari, Metodologi Pengajaran Bahasa. Jakarta: Gramedia Pustaka Utama. 1993.

S. Sugianto, Desain Penelitian Kualitatif, Surabaya: Puslit IKIP, 1989

Sugiyono, Memahami Penelitian Kualitatif, Cet. I; Bandung: Alfabeta, 2008

Thuaimah, Rusydi Ahmad, al-Marja' $f i$ Ta'lim al-Lughah al-'Arabiyah, Mekkah: Jamiah Umm al-Qura, 2010
Ushaili, Abdul Aziz bin Ibrahim. Psikolinguistik Pembelajaran Bahasa Arab, Terjemahan Oleh Jailani Husni, (Bandung: Humanora, 2009

Zulhannan, Teknik Pembelajaran Bahasa Arab Interaktif, Jakarta: Raja Grafindo Persada, 2014 